\title{
WELLNESS CONSTRAINTS AMONG INTERNATIONAL UNIVERSITY STUDENTS TRANSITIONING THROUGH COVID 19
}

\author{
Mr J Dorasamy ${ }^{1}$, Prof N Dorasamy ${ }^{2}$ \\ ${ }^{I}$ PHD Student: Faculty of Health Sciences, Durban University of Technology \\ hellojirushlan@gmail.com \\ ${ }^{2}$ Faculty of Management Sciences, Durban University of Technology \\ nirmala@dut.ac.za
}

\section{INTRODUCTION}

The World Health Organization (WHO) in March 2020 declared Covid 19 a pandemic, due to the global and rapid spread of a novel coronavirus (WHO, 2020). The Covid 19 pandemic being highly infectious and unpredictable has disrupted social, economic, environmental and political spheres of life. Globally, people have ventured into a "lockdown world", increasing uncertainty about their future amidst the Covid 19 pandemic. As a result of the pandemic, social alteration has taken the form of social distancing, self-isolation and self-quarantine. Many were unprepared for the shift from the "normal", propelling undue stress under the new normal way of doing things during the current global pandemic crisis. This has been accompanied by social, emotional and mental effects, as the ongoing and fluid nature of the pandemic has created uncertainty for many people. The Covid 19 pandemic, as a multidimensional stressor affecting wellbeing, has affected individuals, families, educational, occupational, and broader societal systems.

The higher education sector has also been severely affected by the disruptions of Covid 19. Within the higher education environment, students had to leave campus residences; staff and students worked virtually; and online learning was adopted. In adapting to the new normal, international students studying in face to face programmes have been affected by the absence of peer contact, lack of on campus learning, burnout and being away from their families. This undoubtedly affects student wellness and their ability to cope with an unprecedented pandemic.
As universities entered this unfamiliar and uncertain period of emergency management during Covid 19, student support services play a critical role in addressing student health and wellness. Universities need to understand the multi-dimensional effects of Covid 19 on the wellness of students, so that appropriate responses may be implemented. Virtual support and care has become the mode to mitigate risks facing students.

\section{COVID 19 AND HIGHER EDUCATION}

Society is irretrievably destroyed due to the loss of lives and jobs; and diminished wellness from the pandemic. The enduring demands from the Covid pandemic has invariably exceeded the capacity of many government's to prevent the escalating magnitude of the consequences. As reported by UNESCO (n.d), the disruption caused by Covid 19 has been unparalleled in the history of education worldwide. While public health concerns triggered the disruption, the resulting consequences has led to major changes, including the higher education landscape. As reported by Krishnamurthy (2020), the lives of students and faculty abruptly shifted to remote teaching and learning through the use of digital technologies. From the perspective of enrolments by international students, social isolation has placed universities under tremendous pressure financially, as the threat of attrition or decreased new enrolments potentially impact the financial and economic certainty of universities.

While universities face multidimensional impacts, students are affected in significant 
ways as well. As commented by Naidoo and Cartwright (2020), the disruption to daily academic and social routines affects the sense of safety, self-regulation, safety, predictability and structure among students. This is significantly aligned to personal planning, decision-making, productivity and motivation areas being negatively affected.. For example, university students experiences in countries which imposed lockdown included cancellation of courses; campus and residence closures; transition to online learning; disruption to research; cancellation of workplace experiential learning and internships; and changes in assessments (Hamza, Ewing, Heath \& Goldstein, 2020; Arnett, 2016; Duffy, Twenge, \& Joiner, 2019).More so, not all universities engaged in online teaching prior to Covid 19 , compelling them to adopt online learning without compromising high quality education. Many students were unprepared for such a transition.

Negative wellbeing experiences during Covid 19 can profoundly affect health and performance of university students. As a precarious group, international students generally encounter multiple stressors on a daily basis, which are both contemporary and historical in nature. Such multiple stressors may potentially drain students emotionally and mentally; exhaust their coping resources; and compromise resilience in their personal and academic lives (Van Breda, 2017).In particular, concerns have been raised about the extent to which virtual shifts in teaching and learning practices are contextually relevant and student-centered for international students from diverse cultural backgrounds (Naidoo \& Cartwright, 2020). Thus, the plight of this vulnerable group is associated with pronounced challenges and needs. More especially, international students under confinement due to social isolation measures experienced uncertainty over their status in their country of study; liberty deprivation; fear of being infected with no family support; and the mental and emotional effects of emergency remote learning $(\mathrm{Li}$, Cao, Leung, \& Mak, 2020).
University students are a vulnerable population group, showing higher rates of depression, anxiety, suicidal ideation and less likely to seek support for fear of being stigmatized (Chandratre, 2020). International students based in foreign countries are just as vulnerable, and may face additional burdens associated with Covid 19 such as the need for being around family during crisis situations. Additionally, the rapid pace of changes and challenges such as social alteration; mode of delivery; loss of jobs; access to resources; coping with infection and loss of lives; and the lack of personal protective equipment triggered stress, anxiety and fear ( $\mathrm{Li}$ et al., 2020). The negative effects on international university students, especially being away from home and family, can translate into negative emotional and mental health issues. This may lead to other unhealthy behaviours such as substance abuse, obesity and inactivity.

Thus, all the phenomena threatening society during this health crisis must be critiqued, so that destructive threats to society can be derailed (Lumpkin \& Bacq, 2019). Additionally, Yoo (2020) called for solidarity from governments and the public in general to help to mitigate the devastating impact. The impact on higher education is no exception.

\section{WELLNESS DIMENSIONS}

There is a general understanding that wellness is a holistic, multidimensional concept, encompassing various aspects of human life, which complement one another. Extant literature on the description and definition of wellbeing shows that most authors define wellness as an integrated concept that attempts to combine various aspects of human life (Arcuri, 2018; Cooke, Melchert \& Connor, 2016; Sibi \& Abraham, 2017: 50). These include the physical, psychological, career, social, spiritual, economic/financial, intellectual, climate, culture, and environment (Miller \& Foster, 2010). These dimensions interact with each other, and in a situation whereby one dimension is compromised, the interference with other dimensions becomes 
key (Cooke et al., 2016; Sibi \& Abraham, 2017). Association and interaction between the various dimensions is the dynamic nature of wellness based on the changes that one experiences throughout life (Cooke et al., 2016).Thus, COVID-19 has laid bare the interconnectedness of the various dimensions of wellness on human existence.

Undoubtedly, the precarious life of international students living abroad, has been affected in almost all dimensions of wellness (Salameh, Hajj, Badro, Abou, Selwan, 2020). In the context of "multiple hits", the combined effects of Covid 19 may affect overall student wellbeing. International university students based in their country of study, are a vulnerable population who have experienced wellness challenges. For example, it can be argued that while the use of technology during social distancing presents opportunities for students to reduce anxiety and stress; build community; and prevent loneliness, not all students were able to cope with the unsurmountable pressure arising from the pandemic (Papouli, Chatzifotiou \& Tsairidis, 2020). Thus, investigating the impact of Covid 19 on the wellness of international students is of paramount significance to ensure appropriate and real time responses.

\section{- Emotional and mental concerns}

Many studies have reported that as not all students are familiar with online learning, it can be stressful and demotivating. This can impact the mental health of international students as they are away from family and friends; and do not have much support during isolation. For example, the study by Lee (2020) reported that concerns about food, family, finances, worry about being potentially Covid positive and technological constraints among students affected their mental health. Further, students in various programmes which require clinical placement experiences have been retracted. More so, students who are required to write licensure exams are delayed. Invariably, such delays and displacements caused by travel bans and social isolation has triggered anxiety among students, affecting their emotional, mental and physical well being.

Poor health and wellbeing undoubtedly impacts academic and non-academic performance, often resulting in the worsening of health related issues. While social alteration measures are necessary to stop the spread of the virus, increased risks such as loneliness, isolation, and anxiety among university students may potentially increase (Choi, Heilemann, Fauer \& Mead, 2020). More so, with limited finances and medical aid options available for international students, maintaining wellbeing can be a major concern.As reported by Salameh, Hajj, Badro, Abou, Selwan (2020), financial insecurity is associated with higher stress and anxiety levels. Additionally, being infected; access to treatment and medication; worry about family and friends; concerns about food security; and other psychological reactions have size effects on overall well-being (Cooke, Melchert \& Connor, 2016). In support, Zhang, Wang, Rauch and Wei (2020) reported that evidence showed that those who continued working during Covid 19 experienced less negative impact on their mental wellbeing compared to those who became unemployed. Likewise, during Covid19, many international students who rely on part time employment in the country of study lost their jobs, significantly affecting their wellbeing. In addition, Charles, Strong, Burns, Bullerjahn and Serafine (2020) argued that Covid 19 and societal disruption is stressful, even if people are not infected. This is supported in the study by Husky, KovessMasfety and Swendsen (2020) which reported that students who did not relocate to their families during the pandemic reported higher levels of stress and anxiety.

More so, if there is no culture of wellness within universities, this can impact the development of individuals, communities and societies both locally and globally. In this regard, Melnyk, Amaya, Szalacha and Hoying (2016) argued that poor wellness cultures promote poor lifestyle behaviours and beliefs, thereby contributing to low levels of resilience during crisis situations. Thus, if students are not psychologically and emotionally engaged, 
positive student outcomes can compromised, especially during a pandemic like Covid 19.

\section{- Learning}

Most higher education institutions have embarked on online teaching and learning during Covid 19 to reduce transmission of the virus. Students who have enrolled in contact programmes, have endured stress related to online learning and completion of tasks (Aguilera-Hermida, 2020). Remote learning has taken the form of asynchronous classes where lecturers prepare recorded lectures, and students attended online classes at their own pace or syn- chronous classes which occurred at specific times via a specific medium. While there is evidence from some research studies that performance among university students did improve during Covid 19, learning processes were affected (Aguilera-Hermida, 2020). Also, since studies reported that many students continue to value physical interaction and were willing to pay higher fees to ensure face to face learning, the value for them had been altered (Eachempati \& Ramnarayan, 2020; Francis, 2019; Krishnamurthy, 2020). According to Kemp, Palmer, and Strelan (2019), the transition from face to face learning to online learning has necessitated instructional redesign and planning. More specifically, online learning material must be provided in ways which support emergency remote learning. This is an important consideration, since many students did not choose to venture into remote learning.

However, students may also experience cognitive overload because of constrained information processing capacity. This challenge can be accentuated by students who are from less English speaking groups. Such students may experience lower levels of cognitive engagement because they lack confidence in online learning (Kemp et al., 2019).In this regard, the study by AguileraHermida (2020) reported that students who preferred the face to face mode of delivery had low perceptions of self efficacy, fearing that they may be unsuccessful in their learning. Some of the reasons for preferring face to face learning include interaction with lecturers, reliance on others for motivation and valuing real people to assist in directing their learning (Bower, 2019).

Additionally, as reported by Jackman, Konkin, Yonge, Myrick and Cockell (2020), students withdrawing from placements during the pandemic, especially in frontline health facilities, impacted the availability of health services to meet rising health demands. While there is the possibility of lingering anxiety over a sense of a work placement education cut short and affecting judgement in practice, Shaw (2020) argued that conversely such experiences may develop their reflexive abilities to adapt, capitalize on circumstances and establish a holistic perspective during crisis situations. Apart from this, competing sources of information and lack of information regarding the way forward can be lockdown stressors, especially for students nearing licensure (Stokes, 2020). This may trigger helplessness, hopelessness and directionless, as the length of the pandemic restrictions were indefinite.

Further, students with pre-existing mental health issues are at risk for increased psychological distress associated with Covid 19, thus impacting their learning (Duffy, Twenge, \& Joiner, 2019). For example, loneliness stemming from university closures and social distancing; uncertainty about timeous completion of their studies; and difficulty accessing academic and nonacademic support can exacerbate pre-existing mental health issues, possibility leading to disengagement, relapses and attrition (Arnett, 2016). However, the study by Hamza, Ewing, Heath and Goldstein (2020) reported that students without pre-existing mental health issues showed increased distress during the pandemic compared to those with pre-existing mental health issues. Obviously, both groups of students are disadvantaged, leaving them without the critical credentials for successful entry into the job market, both in their country of study and origin.

Further more, the emergency transition to online learning has bombarded lecturers with 
improving instructional and assessment materials; using multiple technology platforms; and adjusting their teaching times. Bower (2019) posited that if lecturers felt overwhelmed in the transition, then the detrimental effects on students should not be ignored. Additionally, Kemp at al. (2019) argued that apart from technological issues associated with online learning, the pedagogical and instructional challenges must also be considered. More so, such challenges may potentially lead to the fiasco among international students in not being ready to work at any place outside their parent country (Dhahri, Arain, Memon, Rao \& Mian, 2020). This may generally affect a smooth transition from being a student to being employed as graduate.

However, despite many studies reporting that students struggled with emergency remote learning, Papouli, Chatzifotiou \& Tsairidis noted that many students did use the social isolation to learn new skills and social capabilities to make their lives more useful. Constant learning and adapting to new circumstances are important during uncertain times.

\section{- Environmental}

Covid 19 has impacted the environment in which people live, work and socialise, leading to losses in social connectedness, decreased physical activity, changes in social roles, and new stay-at home routines. Stressors like having too many things to do at once, findings courses too demanding, struggling to meet academic expectations; and not enough time for rest may become accentuated in the move to online learning and social isolation.

Often, international students rely on part time work as a source of income. Lock down stipulations affected their financial status due to unemployment; limited financial support for international students; and higher cost of living due to rising food prices. Invariably, such environmental changes have affected coping strategies, feelings of positive effect, and access to rewarding experiences (Lai et al.,
2013).As argued by Schleider, Dobias, Sung and Mullarkey (2020), uncertainty and prolonged exposure to anxiety inducing situations like changes in daily routines, place of residence and financial security may potentially increase psychological difficulties, especially if individuals do not have the resources to address them.

Being a new, pervasive and relatively uncontrollable pandemic, the stay at home restrictions has created limited opportunities for people to escape. Thus aggravated, maladaptive interpersonal patterns, may elevate risks of suicidal thoughts and behaviours. In the instance of international students, long term inability to adapt and mobilize resources may likely lead to moderate to severe levels of distress, anxiety and depression (Lai, La Greca, Auslander \& Short, 2013). More so, such psychological stressors are associated with increased emotional reactivity and maladaptive emotional regulation (Gruber et al., 2020).

Covid 19 has placed restrictions on physical activities like exercising, sport and outdoor activities, which are important for maintaining mental wellness and a healthy body. Further, WHO (2020) opined that physical activity is critical for building social interaction, integration and self-expression. An unconducive Covid 19 environment for such activities, has evolved into sedentary time. This has the potential for weight gain, unhealthy eating, obesity and other health related problems. Such effects may potentially affect academic success of university students. Since healthy behaviours are beneficially regulated when individuals are exposed to regular physical activities and structured daily routines, this has to be optimized during Covid 19 to ensure wellness.

Additionally, from a developmental perspective, university students need to engage in reward seeking behaviours with their peers and faculty, which will allow them opportunities for exploration and growth (Gruber et al., 2020). Relatedly, some who are forced to return home from university residences, may find a stalling of their key 
developmental milestones, in view of family restrictions on their freedom of choice. As reported by Forbes and Dahl (2012), disrupted social lives after a period of independence and for which students are unprepared may not be welcomed by students. Specifically, staying at home can involve domestic stressors such as conflict, sharing confined spaces and increased chores, which can exacerbate recovery and wellbeing challenges. This may potentially result in mental health and social challenges.

\section{- Social}

It is well documented that social alteration, resulting in reduced social interaction, during Covid 19 affects mental and physical wellbeing (Gruber et al, 2020; Brooks, Webster, Smith, Woodland, Wessely, Greenberg \& Rubin, 2020). For example, prolonged separation or death of loved ones has impacted roles within families, occupational responsibilities, modes of grieving, interpersonal adversity, and addictive behaviours, Further,for students living in shared accommodation, accessibility to online instruction with cognitive engagement can be challenging, considering the number of individuals in the same pace and the associated distractions. Relatedly, the study by Aguilera-Hermida (2020) reported that studying at home was challenging due to noise; housework; home no longer being a place to relax difficult; and balancing personal life, university and work.

While social alteration measures are necessary to stop the spread of the virus, increased risks such as loneliness, isolation, and anxiety among university students may potentially increase (Choi, Heilemann, Fauer \& Mead, 2020). More so, those with pre-existing wellness issues, may experience exacerbated wellness impairments due to increased fear, isolation and stress associated with the pandemic. Additionally, housing instability, for example being forced to move out of student residences or to move into cheaper accommodation because of loss of income may trigger feelings of helplessness and hopelessness. Within the entire spectrum of country specific responses, international students must be specifically considered since not all responses consider non-citizens.

However, Covid 19 has seen positive changes like pursuing new hobbies; new skills; learning about new technology like Zoom and MS Teams; and learning new languages.

\section{- Use of technology}

The suspension of university activities and move to an online setting, has confounded prevailing pressure among university students throughout the world (Tian-Ci Quek et al., 2019). The study by Dhahri, Arain, Memon, Rao \& Mian (2020) showed that students were stressed and anxious because of the delay in commencing online classes, dissatisfaction with the set up of online classes, adjusting to online learning, delays in exams, and reduced confidence in their graduate credibility. This was compounded in cases where students tested positive. Additionally, Dhahri et al. ( 2020) argued that studies toward some careers like medicine is highly demanding and it cannot be perceived that students in such study programmes are resilient to stress related occurrences. This is evidenced in studies which reported on significant stress experienced by various individuals in the health sciences (Amaya \& Melnyk, 2020; Choi, Heilemann, Fauer \& Mead,2020; Pfefferbaum \& North, 2020).

According to Wang, Shannon and Ross (2013), there are various determinants informing the acceptance of using technology. For example, the attitudes of students toward educational technology directly impacts their learning processes. Further, not all students buy into technology based shifts to wellness and academic support, especially if students construe such changes as incompatible with their personal and socio-economic situations. Hence, university stakeholders need to investigate the perceptions, attitudes and conversancy of students with online support, so that students' buy-in is not hampered. Relatedly,the study by Wang et al. (2013) found that there are negative correlations 
between negative emotions and cognitive processes and learning outcomes. Additionally, if students are not satisfied with the transition to online learning, their motivation to learn is affected. This may result in assignments being submitted late, poor quality of assessments and poor performance. Relatedly, internet connectivity when several people are using the internet at once, slows internet connectivity and timeous completion of tasks (Baloran, 2020).

Moreso, the efficacy of students in using online technology is basedon prior experiences. Without training in using online tools, students may find that they do not have the skills and knowledge to use online platforms which can negatively affect their use of online applications (Kemp et al., 2019). Thus,Hodges, Moore, Lockee, Trust and Bond (2020), argued that online learning has to focus on value and not just quality; new roles of faculty and students; and reinventing teaching, learning and assessment practices. Relatedly, the worldwide technology led transformation within higher education has made it imperative for universities to adopt sustainable online learning models, so that students' learning is value embedded in terms of time, relevance and quality (Francis, 2019).

Despite, widespread reports on the disruption caused by social isolation and the transition to remote learning, Francis (2019) points out that the experiences from Covid 19 can be used to develop universities of the future which are founded on learning personalization, multiple learning pathways and artificial intelligence. Technology explosion and remote learning experiences may likely act as a stimulus to prepare students of the future for a reduced dependence on physical infrastructure in an university environment.

\section{WAY FORWARD}

Though the COVID-19 response to date has focused primarily on mitigating spread and reducing mortality, the pandemic has potentially created a secondary crisis of wellness, which has to be addressed as part of a comprehensive response to building resilience among various groups in society. The sudden disruption caused by Covid 19 overwhelmed the preparedness of international students in terms of psychological, social, emotional and academic readiness. As reported in the study by Xiao et al. (2020), it is fundamentally critical to understand how the pandemic affected the wellness of students. However, since international students are a precarious vulnerable group, the associations between Covid 19 distancing and their wellness is especially important for ensuring that intervention measures are responsive to their specific needs.

While international students need support in the transition to an international university and are expected to abide by behaviour codes, they also need support in transitioning through Covid 19. Shaw (2020) highlighted the vulnerability of students, whose sense of selfefficacy is reliant on positive learning experiences and reinforcement by other teaching and learning support. The COVID-19 outbreak affected and undercut these experiences, compromising valuable gains from university education. As a consequence, Copeland, McGinnis, Bai, Adams, Nardone, Devadanam, Rettew and Hudziak (2021) reported that social isolation, uncertainty, economic and health effects of Covid 19 has decreased wellness behaviours among university students. For example, staff and students must be appropriately trained in the use of technology platforms not only for purposes of meaningful academic engagement, but also for well being support.Such training should also cover issues relating to ethical, legal, privacy, confidentiality and practical risks associated with technology based interventions, as this is critical for meaningful and authentic engagement (Naidoo \& Cartwright, 2020).Thus, skills capacitation and technology support is needed to assist students to negotiate the shift to emergency online teaching and learning; and support initiatives.

As postulated by the Self Determination Theory, individuals need competence, 
autonomy and relatedness to be managed in an integrated manner to ensure wellbeing (Gibbs, 2020). From a student's perspective, Covid 19 has triggered a catalyst for universities to consider ways of strengthening wellbeing of international students, considering the peculiarities and complexities facing them. For example, Naidoo and Cartwright (2020) reported that females are a high risk vulnerable group to exploitative sexual practices to support themselves and their studies. The pandemic has intensified the vulnerability of this group, both for local and international female students, thus posing new wellbeing challenges. Further, especially during times of crisis, the "relational self" of students becomes fundamentally important, as they depend on family and their social networks for their continued existence ( Verde, 2017). Also, government initiatives should further consider working directly with universities to create supportive environments for international students and to create systems that allow for closer monitoring of such students (Gibbs, 2020). Such collaboration, is more targeted and allows forresources to be deployed directly to such students, who may not necessarily benefit from programmes targeting in-country citizens. This may also help to identify high risk students, who may need to travel back home for further health and family support, especially if international health insurance has financial and health service restrictions.Therefore, a comprehensive, multi-tired support approach from university stakeholders is an imperative

Adtionally,the pandemic has created an unprecedented change culture in all areas of university education, with years of accepted practices in teaching, learning and assessment becoming inappropriate under Covid 19 conditions (Gibbs, 2020).It requires universities to consider whether they will ever return to old educational methodologies and pedagogy; the quality of newly implemented methodologies and pedagogy under emergency conditions; and the adoption of best practices in faculty and student wellness (Eachempati \& Ramnarayan, 2020). Thus, thinking about old and new practices, evaluation of new innovations and research on the educational melting pot regarding teaching, learning, assessment and wellbeing are imperatives in advancing to the new normal (Gibbs,2020). As argued by Tolsgaard, Cleland, Wilkinson and Ellaway (2020), universities have to make sacrifices and choices, so that approaches to teaching, learning, assessment and wellbeing are shaped by transformation aligned to needs identified during the disruption to the normal within universities. Despite the disruptions caused by Covid-19 social distancing measures, instructional continuity must prevail through emergency remote teaching (Hodges, Moore, Lockee, Trust \& Bond, 2020). While it is a temporary shift to online learning, students should not be subjected to a totally newly designed teaching and learning ecosystem which has not been tested. Reliable educational support in the short term, readily available to students should be the primary objective of universities. As argued by Hodges et al. (2020), students should have coherent and cohesive learning experiences during Covid 19, underpinned by comprehensive support systems for digital learning, methodologies and contexts.

Further, since many universities rely on international students for their annual income, the financial stability of such institutions during and post Covid 19 may be affected. More so, travel restrictions may have catastrophic effects on face to face programmes for international students. This may necessitate universities to offer their programmes online to international students. This requires an overhaul in organizational management and educational offerings However, not all programmes are conducive to online offerings, such as careers in the health sciences. Thus, Gibbs (2020) argued that a well coordinated and cooperative approach in adjusting to the new normal is an imperative to ensure curriculum, organizational and faculty efficiency.

Higher education institutions must provide effective communication about available wellness resources and opportunities. Online support requires efffective collaboration and coordination across all academic and non- 
academic departments within universities, as well as with external stakeholders such as government departments so that an integrated approach can promote the sharing of resources across audiences throughout the pandemic and subsequent waves. Some of the innovative communication strategies used by universities included the creation of mobile QR codes, Covid 19 intranet hubs, virtual presentations, and partnerships with state health departments to engage staff and students with online resources. Such engagement is invaluable for bidirectional information sharing, and collating feedback on student needs and concerns. This must be reinforced with investment in resources and commitment by leadership and management in wellness programming, so that continuous wellness support is available, even outside of crisis situations. In support, Pfefferbaum and North (2020) argued that building a robust wellness culture within universities is pivotal, so that the health and wellness of staff and students during any pandemic or crisis is not adversely affected.

Relatedly, wellness initiatives must be responsive to a virtual environment, so that it is accessible during social alteration. Virtual initiatives in the form of webinars, apps, emails, online class platforms and web links are some of the initiatives which can address diverse needs. More so, real time sharing of scientific information about COVID-19 is an effective means to enhance public responsiveness and is key to providing realtime guidance for effective interventions from various sectors in society. Since, university students, especially international students, are a vulnerable population group, social media is a critical medium to engage with students regarding Covid 19. However, considering the extensive nature of misinformation, there is a need for increased health information dissemination and engagement online through reliable channels of communication (Chesser, Ham \& Woods, 2020). Thus, while the need for frequent communication is necessary for critical information sharing, it is equally important to avoid overwhelming students with an overload of communication from various university sources (Regehr \& Goel, 2020). However, as argued by Usher, Bhullar and Jackson (2020), media sensationalism is difficult to combat, thus creating a need for students to be capacitated to manage communication from various sources.

Another consideration, is for the curriculum to include areas like communication, resilience building, time management and stress management as part of general education, since these focus areas proactively prepares students for personal crisis management which is integral for managing the long term effects of crisis situations like Covid 19. For example, measures of resilience from university wellness programmes ought to be one of several important initiatives targeting this core group as the complexities of Covid 19 and its effects is distinguishable from other pandemics or natural disasters. This has been suggested in literature recommending coping measures for students, since they are a vulnerable group who need exposure to support and coping measures (Horesh \& Brown; 2020; Karp \& Levine, 2018; Huang, $\mathrm{Lv}$ and Wu, 2016).As such, Xiao (2020) recommended including pandemic preparedness education within the curriculum as a critical coping mechanism.

According to Charles, Strong, Burns, Bullerjahn and Serafine (2020), students generally fear stigmatizatioin and may be reluctant to reach out for social and health services support. Being an out-group, from diverse cultural backgrounds, international students may fear stigmatization, thus preventing them from seeking health services, menial jobs and other support such as food parcels. Public stigma associated with mental disorders; and financial and food insecurity is quite high, and it not certain whether such attitudes will change during and beyond Covid 19. Relatedly, Gibbs (2020) argued that the message associated with "social distancing" counters support, humanization and disclosure, inherently sowing the seeds for further stigmatizing. Thus, the perceived psychological threat accompanying stigmatization requires interventions which encourage students to seek help during Covid 
19. Discretionary and remote support initiatives are important considerations. In this regard, Husky et al. (2020) suggested health services accessible through chat platforms like telehealth and online services can be effective in treating mental health being, but within reasonable parameters considering the level of severity of the symptoms, and ethical parameters of service provision. Relatedly, continuous "check in" modes of communication is integral to maintaining wellness amidst the chaos caused by Covid 19(Norwood, Ursano, Fullerton,2000).

Considering major changes in all dimensions in the lives of international students during Covid 19, helpful and innovative approaches to help students in their overall wellness is an imperative. Embracing a paradigm shift in the lives of international students in such unprecedented times is not negotiable (Chandratre, 2020). Thus, if international students do not have coping strategies to mitigate the impact of the pandemic on their studies, it is likely that their academic performance and long term wellbeing will be negatively affected.Thus, while universities need to continue to support the continuing needs of students with pre-existing mental health challenges since they are at higher risk, they also need to prioritize early intervention and prevention programmes for students showing declining mental health during social isolation ( Hamza, Ewing, Heath \& Goldstein 2020). Relatedly, the findings by (Xiao et al., 2020) underscored the importance of providing essential support to students even if they are well informed, since they are a vulnerable group.Thus,there is strong advocacy for support programmes which proactively prepare students for unprecedented crisis situations, which is critical for coping with the multifaceted impacts of Covid 19.

\section{CONCLUSION}

COVID-19, as an emergency situationat the time of writing this article, has not ended and there is no certainty when it will end. Thus, all sectors in society have been prevented from moving into restart and recovery . Equally so, universities had to manage the exponential demands emerging from social isolation during Covid 19. As reported by Regehr and Goel (2020), universities need to be capable of providing effective responses which safeguards the interests of key stakeholders, such as students. Relatedly, their business continuity framework has to address risk mitigation, including the social, emotional, mental and academic aspects affecting students (SchWeber, 2008). This needs attention, since students enrolments impact the financial sustainability of universities. Thus, Usher, Bhullar and Jackson (2020) posited that building university resilience to respond to any crisis is critical, since universities must be committed to act in real time.

However, Covid 19 has necessitated remote and virtual responses. While universities are expected to promote the well-being of their students under normal circumstances considering the pressures, demands and burnouts they face, they need to support and address student needs under the "new normal". The effects of the crisis may continue, severely affecting all dimensions of human wellness.As pointed out by Salameh, Hajj, Badro, Abou, Selwan (2020), since the uncertainty and instability cause by Covid 19 will be pervasive for much time, universities need to develop innovative measures to address multidimensional needs of students under the " new normal" environment. Prioritization of support, especially for international students in social isolation, is critical for their overall wellbeing. However, it must be noted that larger and financially well endowed universities may be better prepared to manage unprecedented crisis situations like Covid 19, with a vast array of support services offered online during the pandemic.

During emergencies such as COVID-19, it is important to note that the wellness of individuals can be severely compromised, especially if there were pre-existing wellness issues. It can be argued that the greater the perceived disruption by COVID 19, the greater 
the impact. This disruption may increase, especially for international students who are away from their families and long standing social networks; and have to deal with disruptions to their typical university life. More so, socialisation into life at university is a professional role in itself, including adjustment and internalising their roles as students. From the perspective of international students, Covid 19 has personally cost them this socialisation experience in their country of study, thereby impacting their adjustment into university life. Thus, in the case of international students, university commitment to providing a welcoming and safe place for them during social isolation must be time sensitive.

Undoubdtedly,the experiences of international university students has been impacted in areas such as mental health, financial well-being, academic performance and social isolation. Considering that Covid 9 has created a long road of uncertainty ahead of us, it is imperative that the Covid 19 burdens afflicting international students are alleviated through support from all sources in the country of study.It is important for higher education institutions to nurture a sense of altruism, especially to international students who are based in their countries, since they are global assets, whose future worth cannot be dispelled.

Strong leadership; robust collaboration and coordination; investment in technology and staff; timely communication; and accessibility to continuous support and wellness programmes are key success factors contributing to evolving support efforts.Notwithstanding widespread concern about Covid 19 effects, there is a paucity of empirical literature on COVID-19 and wellness among international university students.Thus, there is a social responsibility to identify the wellness impact of Covid 19 on this vulnerable group, so that effective prevention and mitigation strategies can be formulated and implemented for continuous responses to the pandemic and future pandemics. However, it is not all doom and gloom as Covid 19 did present positive outcomes to some students, who were able to navigate through uncertainty, stay positive, find new pathways to obtaining knowledge, and stay driven to serve their wellbeing. Ultimately, all lessons learnt should be used as a catalyst for current and future Covid 19 related interventions.

\section{REFERENCES}

Aguilera-Hermida, A.P.2020. College students' use and acceptance of emergency online learning due to COVID-19. International Journal of Educational Research Open, 1-8.

Arcuri, N.M., 2018. Counseling Relationship Experiences for K-12 School Counselors Who Also Fulfill the Role of Anti-Bullying Specialist. Journal of School Counseling, 16(5), 5-10.

Amaya, M. \& Melnyk, B.M. 2020. Leveraging System-wide Well-being and Resiliency in Higher Education during the COVID-19 Pandemic.Building Healthy Academic Communities Journal, 4 (1), 1-12.

Arnett, J. J .2016. College students as emerging adults: The developmental implications of the college context. Emerging Adulthood, 4, 219-222.

Baloran, E.T. 2020. Knowledge, Attitudes, Anxiety, and Coping Strategies of Students during COVID-19 Pandemic. Journal of Loss and Trauma, 25(8), 635-642.

Bower, M. 2019. Technology-mediated learning theory. British Journal Education Technology, 50, 1035-1048.

Brooks, S. K., Webster, R. K., Smith, L. E., Woodland, L., Wessely, S., Greenberg, N., \& Rubin, G. J. 2020. The psychological impact of quarantine and how to reduce it: Rapid review of the evidence. Lancet, 395, 912-920. 
Chandratre,S.2020. Medical Students and COVID-19: Challenges and Supportive Strategies. Journal of Medical Education and Curricular Development, 7, 1-2.

Charles, N.E. Strong, S.J., Burns, L.C., Bullerjahn, M.R. \& Serafine, K.M. 2020.Increased mood disorder symptoms, perceived stress, and alcohol use among college students during the COVID-19 pandemic. Psychiatry Research, 296, 1-11.

Chesser, A., Ham, A.D. \&Woods, N.K. 2020.Assessment of COVID-19 Knowledge Among University Students: Implications for Future Risk Communication Strategies.Health Education \& Behavior,47(4), 540-543.

Choi, K.R., Heilemann, M.V., Fauer, A. \& Mead, M.2020. A Second Pandemic: Mental Health Spillover from the Novel Coronavirus (COVID-19).Journal of the American Psychiatric Nurses Association, 26(4), 340343.

Cooke, P.J., Melchert, T.P. and Connor, K., 2016. Measuring wellbeing: A review of instruments. The Counseling Psychologist, 44(5), 730-757.

Copeland, W.E., McGinnis,E., Bai,Y., Adams,Z., Nardone, H.,Devadanam, V., Rettew, J. \& Hudziak, J.J. 2021. Impact of COVID-19 Pandemic on College Student Mental Health and Wellness. Journal of the American Academy of Child \& Adolescent Psychiatry, 60(1),134-141.

Dhahri, A.A., Arain, S.Y.,Memon, A.M., Rao, A. \& Mian, M. A. 2020.The psychological impact of COVID-19 on medical education of final year students in Pakistan: A crosssectional study. Annals of Medicine and Surgery, 60, 445-450.

Duffy, M. E., Twenge, J. M. \& Joiner, T. E. 2019. Trends in mood and anxiety symptoms and suicide-related outcomes among U.S. undergraduates, 2007-2018: Evidence from two national surveys. Journal of Adolescent Health, 65, 590-598.

Eachempati, P. \& Ramnarayan, K. 2020. Ten maxims for out of class learning to outclass the academic challenges of COVID-19. MedEdPublish, 9(1) 89-95.

Francis, T. (2019). What college presidents need to know about student success. Journal of Research on the College President, 3(1),45-52.

Forbes, E. E. \& Dahl, R. E. 2012. Research Review: Altered reward function in adolescent depression: What, when and how? Journal ofChild Psychology and Psychiatry, 53, 3-15.

Gibbs, T. 2020. The Covid-19 pandemic: Provoking thought and encouraging change. Medical Teacher, 42 (7), 738-740.

Gruber, J., Prinstein, M. J., Clark, L. A., Rottenberg, J., Abramowitz, J. S., Albano, A. M., Aldao, A.,Borelli, J. L., Chung, T., Davila, J., Forbes, E. E., Gee, D. G., Hall, G. C. N., Hallion, L. S., Hinshaw, S. P.,Hofmann, S. G., Hollon, S. D., Joormann, J., Kazdin, A. E., Klein, D. N., La Greca, A. M., Levenson, R.W., MacDonald, A. W., III, McKay, D., McLaughlin, K. A., Mendle, J., Miller, A. B., Neblett, E. W., Nock,M., Olatunji, B. O., Persons, J. B., Rozek, D. C.,Schleider, J. L., Slavich, G. M., Teachman, B. A., Vine,V., \& Weinstock, L. M. 2020. Mental Health and Clinical Psychological Science in the Time of COVID-19: Challenges, Opportunities, and a Call to Action. American Psychologist, 3-19.

Hamza, C. A., Ewing, L., Heath, N. L. \& Goldstein, A. L. 2020. When Social Isolation Is Nothing New: A Longitudinal Study Psychological Distress During COVID-19 Among University Students With and Without Pre-existing Mental Health Concerns. Canadian Psychology, 44, 1-19.

Hodges, C., Moore, S., Lockee, B., Trust, T. \& Bond, A. 2020. The difference betweenemergency remote teaching and online learning. Educause, 1-5.

Horesh, D. \& Brown, A.D. 2020. Traumatic stress in the age of COVID-19: a call to close critical gaps and adapt to new realities. Psychological Trauma: Theory, Research, Practice, and Policy, 12 (4), 331-335.

Huang,Y.; Lv, W., Wu, J.2016. Relationship Between Intrinsic Motivation and 
Undergraduate Students' Depressionand Stress: The Moderating Effect of Interpersonal Conflict. Psychology Rep., $119,527-538$.

Husky, M.M. Kovess-Masfety, V. \& Swendsen, J.D. 2020. Stress and anxiety among university students in France during Covid-19 mandatory confinement. Comprehensive Psychiatry, 5, 1-13.

Li, H.Y., Cao, H., Leung, D.Y.P.\& Mak, Y.W. 2020.The Psychological Impacts of a COVID-19 Outbreak on College Students in China: A Longitudinal Study.International Journal of Environmental Research and Public Health, 17, 1-11.

Jackman, D., Konkin, J., Yonge, O., Myrick, F., Cockell, J. 2020. Crisis and continuity: Rural health care students respond to the COVID-19 outbreak. Nurse Education in Practice, 1-8.

Karp, J.F. \& Levine, A.S. 2018. Mental health services for medical students - time to act. New England of Journal of Medicine, 379 (13), 1196-1198.

Kemp, A., Palmer, E., \& Strelan, P. 2019. A taxonomy of factors affecting attitudes towards educational technologies for use with technology acceptance models. British Journal Education Technology, 50, 2394-2413.

Krishnamurthy, S.2020. The future of business education: A commentary in the shadow of the Covid- 19 pandemic. Journal of Business Research,117, 1-8.

Lai, B. S., La Greca, A. M., Auslander, B. A. \& Short, M. B. 2013.Children's symptoms of posttraumatic stress and depression after a natural disaster: Comorbidity and risk factors. Journal of Affective Disorders, 146, 71-78.

Lee, J. 2020. Mental health effects of school closures during COVID-19.Lancet, 4(6), 421.

Lumpkin, T. \& Bacq, S. 2019. Civic wealth creation: A new view of stakeholder engagement and societal impact. Academy of Management Perspectives, 33(4), 383-404.
Melnyk, B., Amaya, M., Szalacha, L.A. \& Hoying, J. 2016. Relationships Among Perceived Wellness Culture,Healthy Lifestyle Beliefs, and Healthy Behaviors in University Faculty and Staff: Implications for Practice and Future Research. Western Journal of Nursing Research, 38(3), 308-324.

Miller, G. and Foster, L.T., 2010. Wellness frameworks and indicators: An update. Available at:https:// scholar.google.com/scholar. Accessed on 28.01.2021.

Naidoo, P. \& Cartwright, D.2020. Where to from Here? Contemplating the Impact of COVID-19 on South African Students and Student Counseling Services in Higher Education. Journal of College Student Psychotherapy, 1-16.

Norwood, A.E., Ursano, R.J., Fullerton, C.S. 2000. Disaster psychiatry: principles and practice. Psychiatry Quarterly,71(3),207-226.

Pfefferbaum, B. \& North,C.S. 2020.Mental Health and the Covid-19 Pandemic.New England Journal of Medicine, 383:510-512.

Papouli, E., Chatzifotiou, S.\& Tsairidis, C. 2020. The use of digital technology at home during the COVID-19 outbreak:Views of social work students in Greece. Social Work Education, 39(8), 1107-1115.

Regehr, C. \& Goel, V. 2020. Managing COVID-19 in a Large Urban ResearchIntensive University. Journal of Loss and Trauma, 2 (:6-7), 523-539.

Salameh, P. Hajj, A., Badro, D.A., Abou, C. Selwan.D.A. 2020. Mental Health Outcomes of the COVID-19 Pandemic and a Collapsing Economy: Perspectives from a Developing Country.Psychiatry Research, 1-11.

Schleider, J. L., Dobias, M. L., Sung, J. Y., \& Mullarkey, M. C. 2020. Future directions in single-session youth mental health interventions. Journal of Clinical Child and Adolescent Psychology, 49, 264-278.

SchWeber, C. 2008. Determined to learn: Accessing education despite life-threatening 
disasters. Journal of Asynchronous Learning Networks, 12(1), 37-43.

Sibi, P.S. \& Abraham, S., 2017. Wellness Tourism-An Analysis of Tourist Preferences and Perceptions in Puducherry. JOHAR, 12(2), 61-71.

Shaw, S.C.K., 2020. Hopelessness, helplessness and resilience: the importance of safeguarding our trainees' mental wellbeing during the COVID-19 pandemic. Nurse Education. Practice, 44, 1-2.

Stokes, D.C., 2020. Senior medical students in the COVID-19 response: an opportunity to be proactive. Academic Emergency Medicine, 27 (4), 343-345.

Tian-Ci Quek, T., Wai-San Tam, W, X. ,Tran, B., Zhang, M., Zhang, Z., Su-Hui Ho, C.\& Chun-Man Ho, R. 2019.The Global Prevalence of Anxiety Among Medical Students: A MetaAnalysis. International Journal of Environmental Research and Public Health, 16(15), 1-18.

Tolsgaard, M., Cleland, J., Wilkinson, T. \& Ellaway, R. 2020. How we make choices and sacrifices in medical education during the Covid-19 pandemic. Medical Teaching, 42(7), 741-743.

UNESCO. (n.d.). Covid-19 educational disruption and responses. Retrieved from: https://en.unesco.org/covid19/education.

Accessed on 10 February 2021.

Usher, K., Bhullar, N. \& Jackson, D. 2020. Life in the pandemic: Social isolation andmental health. Journal of Clinical Nursing, $00,1-2$.

Van Breda, A. D. 2017. Students are humans too: Psychosocial vulnerability of first-year students at the University of Johannesburg. South African Journal of Higher Education, 31(5), 246-262.

Wang, C., Shannon, D.M. \&Margaret E. Ross, M.E. 2013. Students' characteristics, selfregulated learning, technology self-efficacy, and course outcomes in online learning, Distance Education, 34(3), 302-323.
World Health Organization. 2020. Coronavirus disease 2019 (COVID-19): Situation report 63. Available at: https://www.who.int/docs/defaultsource/coronaviruse/situationreports/20200323-sitrep-63covid19.pdf?sfvrsn=d97cb6dd 2. Accessed on 2 Feb 2021.

Xiao, H., Shu, W., Li, M., Li, Z., Tao,F., Wu, X., Yu, Y., Meng, H., Vermund, S.D. \& $\mathrm{Hu}$, Y. 2020. Social Distancing among Medical Students during the 2019 Coronavirus Disease Pandemic in China: Disease Awareness, Anxiety Disorder, Depression, and Behavioral Activities.International Journal of Environmental Research and Public Health, 17, 1-13.

Yoo, J.H., 2020. The fight against the 2019nCoV outbreak: an arduous march has just begun. Journal of Korean Medical Science, $35-56$.

Zhang, S.X., Wang, Y., Rauch, A., Wei, F. 2020. Unprecedented disruption of lives and work: Health, distress and life satisfaction of working adults in China one month into the COVID-19 outbreak. Psychiatry Research, $288,240-252$. 